\title{
Design a Mobile Application for Children's Tracking in Crowded Environments
}

\author{
Tanweer Alam ${ }^{1}$, Abdirahman Ahmed Hadi², Rayyan Qari Shahabuddin Najam³, Shamimul \\ Qamar $^{4}$ \\ ${ }^{1,2,3}$ Department of Computer Science, Faculty of Computer and Information Systems, Islamic University of Madinah. \\ ${ }^{4}$ Department of Computer Engineering, King Khalid University, Saudi Arabia \\ 'tanweer03@iu.edu.sa, ${ }^{2} 347762730 @$ stu.iu.edu.sa, ${ }^{3} 362051283 @$ stu.iu.edu.sa, ${ }^{4}$ drsqamar@ rediffmail.com
}

\author{
Article Info \\ Page Number: 1 - 08 \\ Publication Issue: \\ Do not Edit
}

\section{Article History}

Article Received: 3 January 2020

Revised: 25 May 2020

Accepted: 02 June 2020

Publication: 20 June 2020

\begin{abstract}
Child Tracking System is a mobile application where the parent can monitor their children location in crowded environments. In addition to children, there is also the elderly people, and the disabled people, so the guidance or the person responsible of them can use this application to track their location. The parent or guidance side will have the application in which they can track, and on the other side, the child or the old person or the disabled person will have device that includes the GPS chip. The main goal of this research is to design an application with system that will help parents to keep track of their children, eventually reducing the cases in which the children or the other mentioned categories of people could be lost. The current used solution to this problem is that the children first have a wearable hand wrist in which they print their parent phone number, so when the child is lost there is a center in which the child is being taken and dealt with care till they contact the parent to come and pick the child up. The problem with the current way that it takes time, and there is a risk that child get totally lost or kidnapped before even reaching to any help, so the new way is better to even prevent them to go far away or to be lost for hours, thus the recovery here will be fast unlike the regular used way nowadays. That goal will be achieved throw systematically objectives starting from studying the existed systems, to planning and analysing, going to designing and implementing, and lastly, testing our own system.
\end{abstract}

Keywords: Mobile Application, Tracking System, Global Positioning System, Crowd Management, Smart Devices.

\section{INTRODUCTION}

Over the years, parents and family greatest concerns when visiting Makkah and Madinah cities for worship was not to lose the child. The very crowded large area with constant movement and relocation of people is very prone to losing a child or an old weak person among the crowd, or even the disabled people. This becomes a major inconvenience to the worshipers who spend a lot of time worrying as well as searching.

The technology revolution has made it very easy to acquire devices for all ages and of many shapes and sizes. This can be positively used by visitors to locate and find their loved ones. The child tracking system on smart devices will help the parents track the movement of the children using GPS technology. One of the reasons why a person may get lost is due the large numbers of people that come to this holy place every year, for example, in 2019, 2.4 million pilgrims came to perform al-hajj [1]. Moreover, the Ramadan season, and Umrah seasons, and not to mention the people who regularly visit Haram from Madinah itself, the residents of Madinah city. The large numbers keep the place busy with people all the time and the population of people traffic varies, reaching 1 million at peak according to [2].

Generally, the loss of persons is an event that could occur in any crowded place. Children, or elders, or 
disabled people being missed in Al Masjid Al Nabawi is a primary concern in Madinah, it's important for every parent that has children, or someone who has people to look after.

Currently, the used way is to monitor and watch back after the person who is lost, through using the records from the cameras on the walls, or by guiding the loose children to a child handling place where they try to contact their parents through the already given band which had the number of parent's phone. But the time in which the child is lost and to be driven to the place could be crucial, in the worst case the child could be kidnapped before someone take $\mathrm{him} /$ her there.

In 2019 the average number of children missing was approximately 1000 per day according to [3]. They were reunited with their parents because of the use of a band that had the number of the parent contacts in case the child was lost, also there is a centre for lost children where they provide them with the best care until they are reunited. Now the maximum technology of this solution is a community based not individual-based, so there is one centre where the child waits. The proposed solution is equally available to the individual as well as organizations. the most important thing, it can track the current location of the missing person. The parent can track the child, and the person who is responsible for elders can track them, and the companion of disabled people can know the precise location of the person. This step could avoid even losing them before they even get lost. The most crucial and critical moments is when the missing person is missing and there is no need for the other parties to be involved to locate him or her thus saving time energy and other resources. This is where the tracking overcomes the normal solution, and cover the abnormal areas that the current solution doesn't.

In this research, the goal we are trying to achieve is to create a system to allow the parents or guardians to keep track their kids or elderly or disabled people when the person is out of sight in the Al-Haram area, to overall not let them be lost, or to recover them fast.
The main objective of the Child Tracking System is to design the tracking system using GPS to prevent child missing events in the haram.

-Study some of the available features used in the child tracking system that fits with the needs of the parent.

-Implement and develop the application that has features and suitably designed, which will be able to assist the parent to monitor the children location in real-time.

-Accredit and verify the developed system by performing unit testing and user interface testing alongside having it tested by the user in the AlHaram to ensure user satisfaction with the application and system provided.

-Guardians need to register an account before using the application and the system.

-Guardians will need to submit their detail to begin using the system.

-The other side (Child or Elder or Disabled Person) will have the GPS.

The android application and system will mainly be targeting the average adult citizen who is guardian to children between the age of 4-12 years of age or elders between 75-90 years or disabled peoples.

The system and application will be working on an Android platform. GPS tracking technology will be used between different devices. The mobile application is responsible for keeping track of the location of the device and showing on the map. We chose the Android platform because it is a free and open-source platform in which the library is easily accessible, whereas the GPS is used for locating the device with the help of the cellular mobile. The application in the device will update the location of the child using the GPS and GLONASS or GPRS technology.

In this introductory section, we gave an overview of the research. We intend to create an Android application that's about tracking either children or old people or disabled people who live position will be tracked using a GPS chip, and on the other hand, the guardian will use the application to monitor them. The goal is to keep the visitors of Haram together and not their beloved ones are lost because 
the place may be overcrowded, and the chances of losing are high. That goal will be achieved to throw systematically objectives starting from studying the existed systems, to plan and design and implement and test our system.

The following sections will be covering the rest; starting from a literature review for the existing systems first. Then we will set up our methodology to develop our system and plan for it. Further, we will discuss the requirements in detail and conduct surveys for that. Then we will start to design the system using the UML diagrams. After that, we will start to implement the system. Next will be testing what we have implemented and verified it. Lastly, we will drive to some conclusions and future work that could be done.

\section{RELATED WORKS}

This section discusses the method and theory regarding the research which gives us the knowledge that gained via resources such as reference book, newspaper, journal, articles and documentation regarding application and research work. A literature study is very essential in that we get more understanding of the GPS tracking system, GSM modem and GPS modem. Besides, the theoretical understanding is very important to lead to this research; to relate it to other researches and available materials and theory and implementation.

\subsection{The Global Positioning System (GPS)}

This well-known system is a navigation system which relies mainly on the satellites. It consists of a network with 24 satellites on a distance of 20350 $\mathrm{KM}$ above the earth surface. It further transmits the microwave signal using earth orbit satellite constellation with medium range, which gives the privilege to GPS receiver to get the values of velocity, time, and position. In order to provide a continuous coverage that is worldwide, there is a process that satellite applies which leads each one of them to go around the planet in one of six orbits in circles, twice a day. The fact is that there are two low power radio signals which are being transmitted by the GPS satellites, named L1 and L2 signals, respectively. It's known that first one has a frequency that equals $1575.42 \mathrm{MHz}$ in the band of UHF, and it's used by the normal users globally [4]. Moreover, we have 3 different bits of information carried by the GPS signal, those are respectively, Pseudorandom Code, Ephemeris Data and Almanac Data. The first code which is Pseudorandom Code is an I.D code that distinguishes which satellite is doing data transmission operation. The second one, the Ephemeris Data, is the data that is used for determining a position and defined as the constantly transmitted data by each satellite. The last part which is the Almanac Data is the one that informs the location of each GPS satellite to the GPS receiver on the other side. Moreover, if the GPS device receives the radio signals, then the exact time of arrival will be noted and will be used to calculate the distance from each satellite in the view [5]. In order to perform calculation regarding the 2-D position (latitude and longitude), the GPS receiver must lock on the signal of at least 3 satellites. Nevertheless, in order to specify the user's 3-D position, the must be four or more satellites used in this situation [4].

To take into consideration, the signals that are being transmitted by the GPS satellites, which are the UHF banded signals, are unable to get through most physical objects or exterior walls such as buildings and mountains which are physically noticeable. As a result, in the urban areas, the problem of the poor signal case will be happening. In addition, the signals can also be weakened by meteorological conditions or tree canopies. There is also one more problem stated as Satellite Signal Fracture which occurs when the standalone GPS navigators are unable of fixing a position within satellite conditions that are poor, then they must wait until a better satellite reception happen to provide the location correctly [6].

\subsection{Global Navigation Satellite System (GLONASS)}

This is a navigation system which works with satellite and it was developed by the Soviet Union in 1976. GPS was not efficient in readings of areas; thigh latitudes (north and south) so GLONASS could cover those [7].

The satellite is positioned in the middle of an orbit which is circular, and with a degree of 64.8 , it is 
inclined at 19,100 km altitude for 11 hours and 15 minutes [8].

It applies the Frequency Division Multiple Access Method (FDMA) channel access method to communicate with the satellites. On the other hand, Code Division Multiple Access techniques (CDMA) since 2008 allows the GPS to be compatible with the GLONASS [9].

\section{Comparison between GPS and GLONASS}

The following two tables represents a comparison of each technology in five stations, the first one was using GPS, and the second one was using GLONASS to ultimately compare how much error of navigation is there, done by [11].

Table 1: Navigation error of GPS only solution in five different reference stations [11]

\begin{tabular}{|c|c|c|c|c|}
\hline \multirow[t]{2}{*}{ Station } & \multicolumn{3}{|c|}{$\begin{array}{l}\text { Error of navigation definitions } \\
(p=0.95)\end{array}$} & \multirow{2}{*}{$\begin{array}{l}\text { Mean } \\
\text { number } \\
\text { of NSV } \\
\text { in nav. } \\
\text { def. }\end{array}$} \\
\hline & $\begin{array}{l}\text { Latitude } \\
\text { (m) }\end{array}$ & $\begin{array}{l}\text { Longitude } \\
\text { (m) }\end{array}$ & $\begin{array}{l}\text { Altitude } \\
\text { (m) }\end{array}$ & \\
\hline Ari & 5.16 & 4.14 & 13.76 & 11 \\
\hline Bellinsgauzen & 6.19 & 4.55 & 16.86 & 10 \\
\hline Bilibino & 4.31 & 4.45 & 15.72 & 12 \\
\hline Vladivosltok & 7.83 & 7.83 & 3.95 & 10 \\
\hline Gelendzhik & 6.57 & 4.34 & 12.12 & 10 \\
\hline
\end{tabular}

Table 2: Navigation error of GLONASS only solution in five different reference stations [11]

\begin{tabular}{|c|c|c|c|c|}
\hline \multirow[t]{2}{*}{ Station } & \multicolumn{3}{|c|}{$\begin{array}{l}\text { Error of navigation definitions } \\
(\mathrm{p}=0.95)\end{array}$} & \multirow{2}{*}{$\begin{array}{l}\text { Mean } \\
\text { number } \\
\text { of NSV } \\
\text { in nav. } \\
\text { def. }\end{array}$} \\
\hline & $\begin{array}{l}\text { Latitude } \\
(\mathrm{m})\end{array}$ & $\begin{array}{l}\text { Longitude } \\
\text { (m) }\end{array}$ & $\begin{array}{l}\text { Altitude } \\
(\mathrm{m})\end{array}$ & \\
\hline Ari & 5.75 & 6.30 & 16.21 & 8 \\
\hline Bellinsgauzen & 6.76 & 7.09 & 16.33 & 8 \\
\hline Bilibino & 6.78 & 6.41 & 15.90 & 9 \\
\hline Vladivosltok & 5.03 & 8.97 & 16.04 & 8 \\
\hline Gelendzhik & 6.85 & 8.25 & 18.72 & 8 \\
\hline
\end{tabular}

According to Table 1, the GPS horizontal accuracy is in the order of 4 to 8 meters whereas, the vertical error is in the order of 12 to 16 meters. In Table 2, the GLONASS the horizontal precision is in the order of 5 to 9 meters and vertical error are in the order of 15 to 19 meters as the accuracy is achieved and is slightly less accurate than GPS.

It is observed that the mean number of GPS satellites available is also higher than the GLONASS. The figures thus have concluded that GPS gives high accuracy as compared to the other [10].

\section{Combined GPS and GLONASS}

GLONASS can be used together with GPS especially in the area of where there is a large amount of cloud coverage. Also, when the device is surrounded by high-rise buildings to increase the availability of satellites. This will improve the overall position precision as the device is being monitored by any of the 55 satellites or more around the world. To preserve the battery, GLONASS will only be activated when the GPS signal is poor. The navigation error provided by GLONASS in combination with GPS, as well as the means number of satellites in view in five different reference stations are shown in Table 3 below.

Table 3: Navigation error of GPS combined with GLONASS solutions in five different reference stations [11]

\begin{tabular}{|l|l|l|l|l|}
\hline Station & \multicolumn{2}{|l|}{$\begin{array}{l}\text { Error of navigation definitions } \\
(\mathrm{p}=0.95)\end{array}$} & $\begin{array}{l}\text { Mean } \\
\text { number } \\
\text { of NSV }\end{array}$ \\
\cline { 2 - 5 } & $\begin{array}{l}\text { Latitude } \\
(\mathrm{m})\end{array}$ & $\begin{array}{l}\text { Longitude } \\
(\mathrm{m})\end{array}$ & $\begin{array}{l}\text { Altitude } \\
(\mathrm{m})\end{array}$ & $\begin{array}{l}\text { in nav. } \\
\text { def. }\end{array}$ \\
\hline Ari & 3.92 & 4.16 & 12.29 & 19 \\
\hline Bellinsgauzen & 4.71 & 5.16 & 12.47 & 18 \\
\hline Bilibino & 4.42 & 4.40 & 11.28 & 20 \\
\hline Vladivosltok & 4.33 & 4.01 & 11.75 & 18 \\
\hline Gelendzhik & 4.79 & 4.93 & 12.73 & 18 \\
\hline
\end{tabular}

Concluded from the comparison, the combined approach will for sure increase the accuracy of the position and so, if implemented in the system, will improve the accuracy and availability of the signal compared to the stand-alone way. It is concluded that the combination of GPS and GLONASS approach is way more efficiently available to the proposed system than the latter to use in tracking [11].

\subsection{Child Tracking System Using Android Phone} In this study, Maghade Satish et. Al. [12] was presented the child tracking system using android 
mobiles. This paper explains about an android application which is used to track the missing child. Currently, lots of mobile phone users have an android mobile. This application works with the help of android phones. This android application based on GPS and SMS services in Android phone. GPS service is used for tracking the exact location of Children. GPS and GSM based systems are used to track the location of Children. Here are two ways that can an application act. Firstly, a GPS based system that is related to the Location services and second is SMS based which is related to the Network providers. When Location-based services do not work then the application uses Network-based services which can be able to send and receive data.

The research developed by them is that which uses two main services that is GPS and short text messages. The first is to locate the position of the person and the second is to notify the parent as well as to communicate with the child. They used the common android system. The simplicity of this was a key feature. The application developed to make a user-friendly approach on both sides [12].

Following, Figure 1 illustrates the architecture of this system where there are two phones one for the child and the other one for the parent. The approach is depending on the messaging between the two phones, the messages contains the location. Moreover, the tracking is done using a GPS satellite.

\subsection{Android Based Children Tracking System}

The Authors [13] proposed in this paper a child tracking system that is based on the android terminal. Currently, all over the world crime against the children in the age of 14 to 17 years is common. Parents always worry about their children whenever they are outside the house. Here, the proposed system consists of two sides out of them one is parent module and child module is the other one [16], [17].

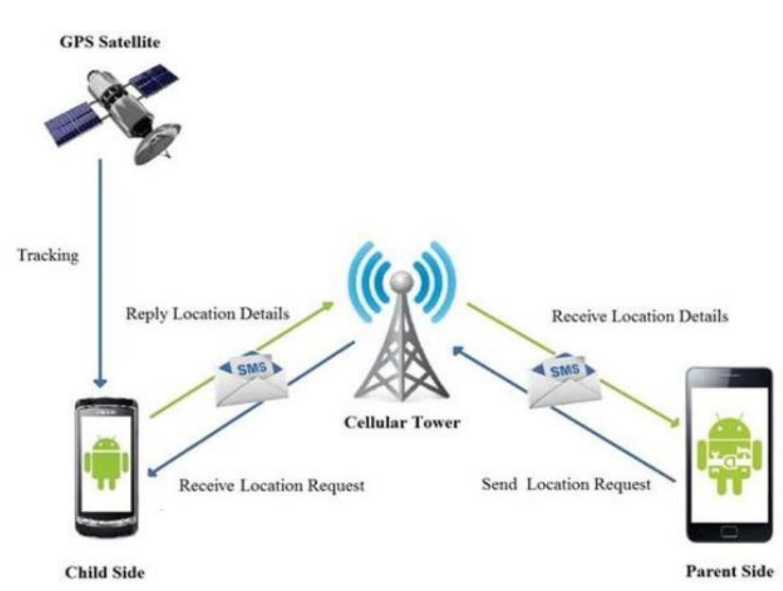

Fig 1: Architecture of Child Tracking System Using Android Phone

The module of the child consists of GSM (Global System for Mobile Communication), GPS (Global Positioning System), ARM7microcontroller (LPC 2148), and voice chip. On the other side, android mobile phone is considered as the parent's module. Giving information about missing child from the school campus is the main focus of this work. Besides, for the safety of both module, there are two android mobile phones. For example, the system tracks the child from home to school, or generally from source to destination [13], [18].

In this paper [13], the authors are described Android Based Children Tracking System with two modules, one for parents and others for their children. The first module consists of ARM7 microcontroller (LPC 2148), GPS (Global Positioning System), GSM (Global System for Mobile Communication) and voice chip where the parent module consists of an android mobile device. In this paper, the authors focused on the information about missing child from school [19], [20].

This research had a child's module. The child's information is transmitted and received using GSM instrument. This module of the child works as a transmitter that is made up of GSM module, ARM7 microcontroller (LPC 2148), GPS module and voice chip and an android device. There is a receiver module which includes an Android mobile phone and database for monitoring. The location of the moving child is tracked by GPS and signal is sent to ARM7 microcontroller. The controller forwards the GPS readings to the GSM board which in return send 
the position of the moving child to two receivers. This allows the parent to get their child's position.

The following figure below, Figure 2, shows a diagram of the system, where there is a voice chip on the microcontroller which then do the speakers job, on the same time it's linked with another device that takes the GPS and send to the computer that has the GSM.

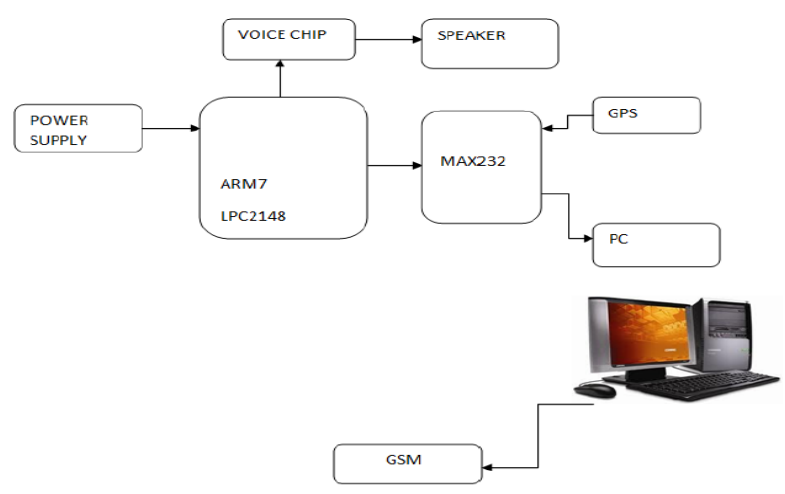

Fig 2: Diagram of Android Based Children Tracking System

\subsection{Peoples Tracking System}

This is a system of two parts was developed by Mo'men Hassan Missawi and his colleagues [14] in their research to solve the problem of lost pilgrims and visitors of hajj. one part is an android application and the other is a server that stores the information of pilgrims and monitors their change of location [21].

They implemented the system and tested it, and they came up that they can find the missing pilgrims' location and display them on a map, and also detect if a person is lost and alert the security. They have as well, made system administrator for managing pilgrim's information's stored in the database, which was tasked to monitor and output results.

They concluded that the system we were able to reduce the problem of missing pilgrims' incidents.

Figure 3 is a demonstration of the system environment, there is the pilgrim and the guider and the helper, they all send the location and receive the notifications. While the administrator can access the database. The application was tested in an android smartphone with GPS service and achieved the goals of the research successfully by:

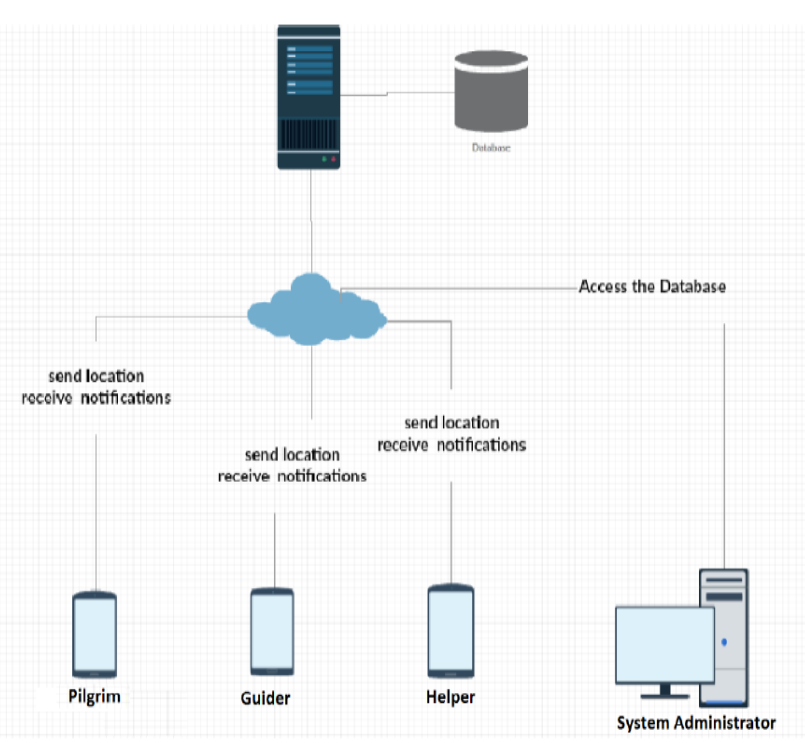

Fig 3: Diagram of Peoples Tracking System -Specified the locations of the pilgrims and their guiders and display them in the map According to the accuracy of GPS, which is acceptable to get perfect results, in terms of reducing space and time of search to find missing persons and find them as soon as possible in the case of loss, and track them all the time to reduce the occurrence of missing.

-Be sending alerts and locations to the authorities of tracking pilgrims.

\section{Implementation of Children Tracking System on Android Mobile Terminals}

Here, the paper focuses on implementing children tracking location system for every time school attending is done by the child. Nowadays more children getting lost, Sen. Charles Schumer (an American politician serving as the senior United States Senator from New York) has proposed that the federal provide funding for tracking devices for autistic children so that

they do not go missing. These proposed tracking devices could also be worn as wristwatches, anklets or in I-cards. the child module includes ARDUINO, Global Positioning System, Global System for Mobile Communication, and a receiver include parent's movable. it is very useful for women safety [15].

\subsection{Existing Tracking Apps}

\subsubsection{Find My Kids}

Find My Kids is a child tracking app for Android and iOS that gives a child's location by triangulating the 
phone's position every 15 minutes to within meters. This is done using a GPS sensor built into a smartphone and Internet communication systems such as WiFi and mobile internet. The application as well does other functions such as it creates a history of the child's location, Sends notifications to a parent's phone if the child leaves a designated area, If necessary, records sound around a child's phone, Defines the settings of a device which prevent normal functioning of the app and helps to fix them, Monitors the child's phone battery and the usage of apps on child's phone.

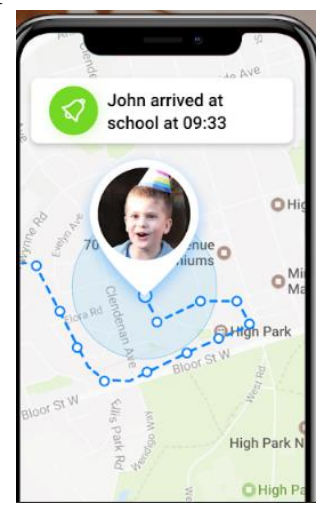

Fig 4: Find My Kids

\subsubsection{Life360 - Family Locator, GPS Tracker}

Life360's mobile tracking app is found on both Android and IOS stores. It displays a well detailed of the map and keeps real time location records which are precise of the child. The app also sends alerts of the child when they arrive and live specific locations. Many members of the same family can keep track of each other. It is suitable for use by everyone as it is simple. Some of the added features are that the app helps the parent track lost or stolen device and will provides a Crash Detection service. In case there is an accident the service of asking for diver or help is provided.

\subsubsection{Family GPS tracker KidsControl}

This mobile application works on both Android and IOS platforms and it is for free. Using GPS system to track it gives real time precise location of the child. KidControl can determine the location even with GPS turned off, via Wi-Fi and LBS cell towers. The app has a feature where the parent can Create "Places" - geofences, for example, "School" or
"House". This will allow you to be notified when your child arrives at school or returns home.

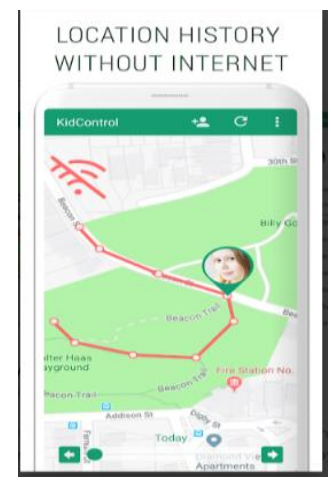

Fig 5: KidsControl

\section{REQUIREMENTS ANALYSIS}

This sectioncontains an elaborated study of how the information was gathered and then analyzed, leading to specifying the requirements in which on top of it the research will be continuously being built.

\subsection{Information Gathering}

To gather information about the current system and to build knowledge for our research we went through two approaches, interview, and questionnaire. Each of them will be going through in the coming subsections.

\subsubsection{Interview}

We conducted an open interview with one of the employees in the Child Care Center in Al-Haram to formulate the knowledge about the existing used system and the approach they follow, we can say that it involves the following processes; First of all, the parent comes with the child to the centre and they give the child a wrist band that has the parents phone number printed on it. Later on, if the child was lost, the security guard will bring the child to the centre, and there the child will be dealt with care, and the employees will contact with the parent using the number that is being printed on children wearable wrist band. Lastly, the parent can come to the centre and take the child.

We further discussed if they were currently using any kind of tracking systems here, and the result was they don't use any tracking systems currently. Moreover, we tried to know if their approach was helpful, and it was because almost all of the cases get returned to their parents, regardless of how much time is being taken. but there were several 
drawbacks if being covered, the enhancement of the current system will exponentially shoot up. Those drawbacks can be outlined in three main things; First, the time from the child being drifted till being guided to the centre could be crucial, and -god may forbid- the child could be in hands of bad people or being kidnapped. Second, the parents themselves sometimes don't reply the call for several reasons, their phones could be battery off, or they don't get the signals, which causes in spending more time in the centre for the child. Last, there are cases in which the lost child didn't even come first there with the parent, and in this case, it requires extra work with the security and police to find the parent, while the child is in the centre.

Afterwards, we ask them about their opinion in introducing the tracking technology to this area, especially to reduce the time in which the child is lost, and to provide live tracking for the parents, which further reduces the problem of time and phone calling availability with the current system. They welcomed the idea and saw it as a very good use of technology to serve humanity, especially in a holy place like Al-Masjid Al-Nabawi.

The last thing we discussed further is how the app should be, and they advised that it should be simple to use to parents because they are of different backgrounds and ages. Besides, the tracking should be working, and the device with the child should be safe.

\subsubsection{Questionnaire}

We distributed questionnaires among 30 random peoples in the area of Al-Masjid Al-Nabawi to gather information and data that will serve us in the basis of knowing the users of the application and their opinion towards the idea, and if they have any recommendation.

Our questionnaire is divided into four parts :the first three parts each contains three questions, while the last part is for suggestions.

\subsubsection{First Part}

First Part contains questions to know about users' categories, backgrounds, and ages.

The first question is "Please choose from the following categories to indicate which kind of persons you are responsible to take care of the child, old person, a disabled person. “

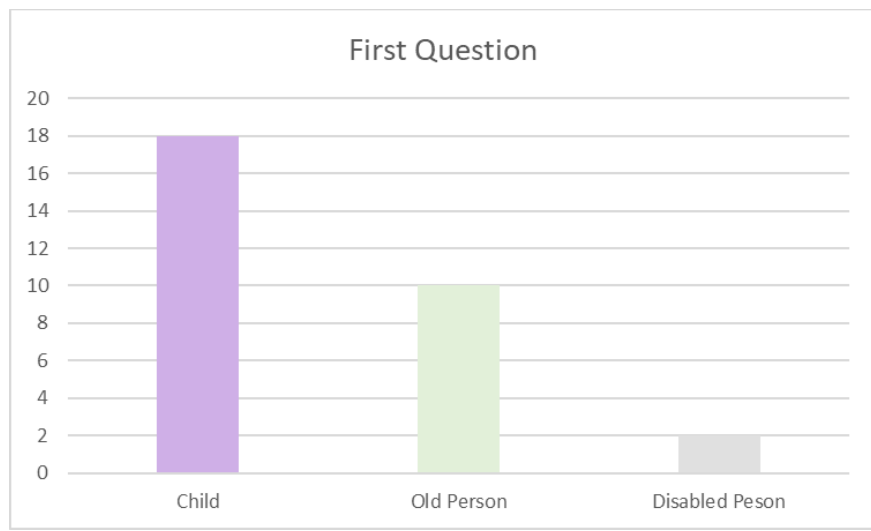

Fig 6: Results of the First Question

The results in Figure 6 show that there is a dominant amount of people that have a child to look after with a percentage of $61 \%$, then in the second place comes the old people. Lastly, there is a proportionally little amount of disabled people who are being taken care of by someone.

The second question is "Do you have children to take care of from age 4-12? “

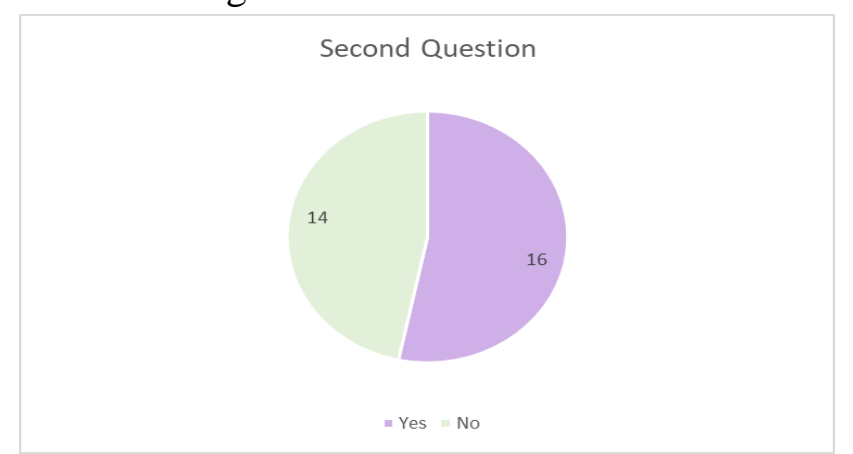

Fig 7: Results of the Second Question

From Figure 7 above, there is a slight difference between having children in these ages.

The third question is "Are you suitable with simple English language as a language for the application? It's clear from Figure 8 that the vast majority are preferring English as the language of the application. 


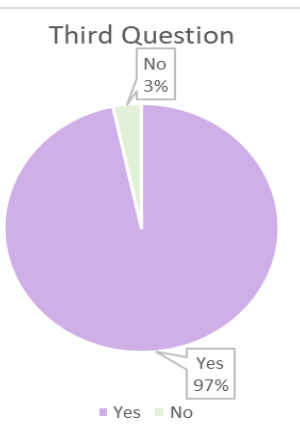

Fig 8: Results of the Third Question

\subsubsection{Second Part}

Second Part contains questions to acquire knowledge about users' experiences in the area of having someone being drifted

The fourth question is "Have you ever experienced having your child or old person or disabled person being lost in Al-Masjid Al-Nabawi before? “

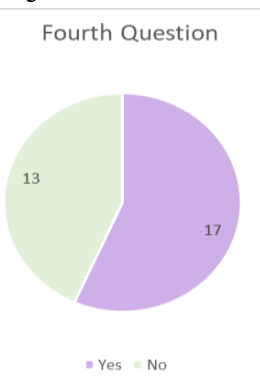

Fig 9: Results of the Fourth Question

In figure 9, we can see that 17 out of 30 peoples experienced having the one they care about to be lost in Al-Masjid Al-Nabawi, regardless of how do they get them back, or if it was a simple drift that happened out of the sight.

The fifth question is "Have you ever witnessed someone else having their child or old person or disabled person being lost in Al-Masjid Al-Nabawi before? “

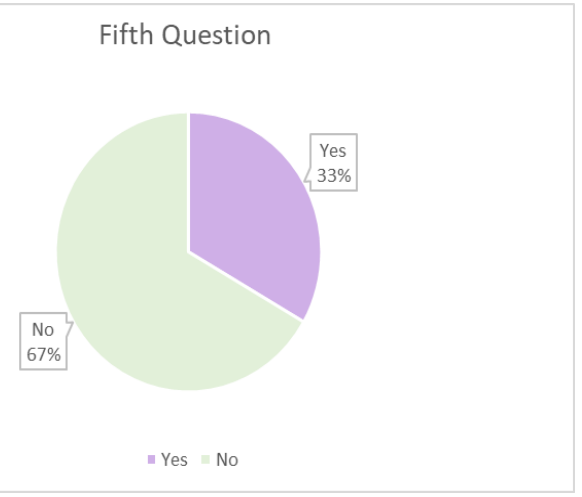

Fig 10: Results of the Fifth Question

In this figure above, Figure 10, there exists one-third cases out of 30 cases, which means 10 cases, in which the people that had lost their beloved ones for a while in Al-Masjid- Al-Nabawi were seen by the participated people in this questionnaire.

The sixth question is "Have you ever witnessed a child or old person or disabled person that was lost in Al-Masjid Al-Nabawi before? “

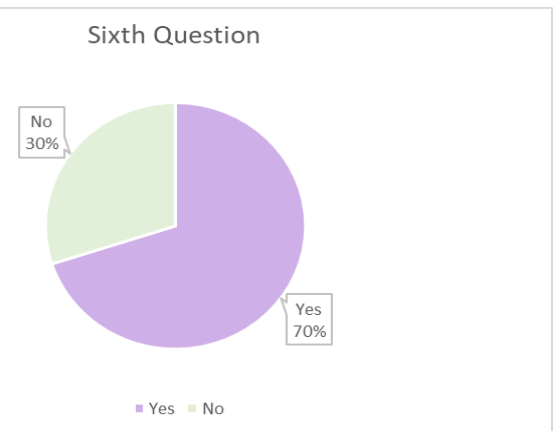

Fig 11: Results of the Sixth Question

In Figure 11, the result shows that there are a lot of cases in which it has been seen that there were lost people that are children or old people or disabled people in Al-Masjid- Al-Nabawi.

\subsubsection{Third Part}

Third Part contains questions to know users' opinions toward the idea of the tracking system.

The seventh question is "Do you think it's a good idea to track your child/old person/disabled person in the area of Al-Masjid Al-Nabawi to prevent them from being lost? “

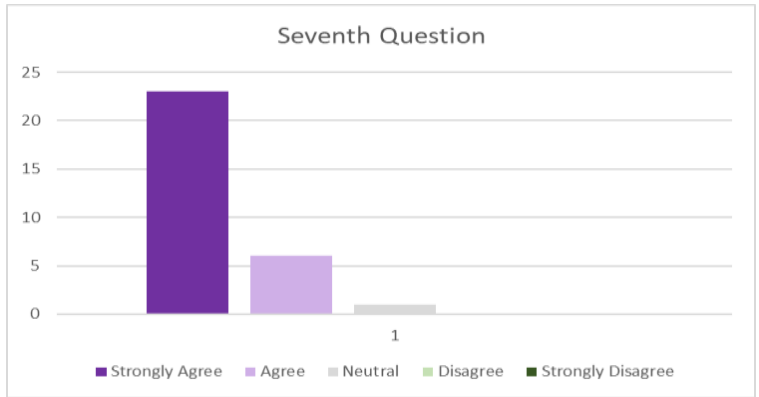

Fig 12: Results of the Seventh Question

Figure 12 shows a very welcoming result, where 23 participants strongly agree, and 6 just agree, and one individual remains neutral towards the idea of using a tracking system to prevent the ones that the person takes care of from being lost. The remarkable notice here is that there is no disagreement of any degree at all.

The eight-question is "Have you ever experienced any tracking technology with your child before? " 


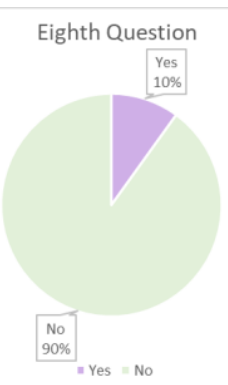

Fig 13: Results of the Eighth Question

Figure 13 reflects that there is no common use of tracking technology by the parents or the responsible persons, thus the majority of users here are facing some kind of new technology in this context.

The ninth question is "Will you use the tracking system if it is being launched by the Child Care Center in Al-Masjid Al-Nabawi? “

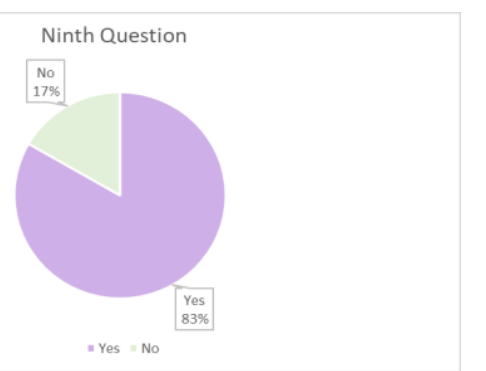

Fig 14: Results of the Ninth Question

It can be inferred from Figure 14 that $83 \%$ of participants, which is equivalent to 25 persons, are ready to use this product if it was launched.

\subsubsection{Fourth Part}

This part is optional if the participants have further suggestions.

We received six responses here; the first one says that the system has to be easy to use. The second one stated that it would be better if there was a button in the device with the child to let the father being notified that the child is lost. The third one proposed that it will be nice to have it as a wearable band. The fourth one claimed that the tracking update has to be quick. The fifth one suggested to let the tracking be from phone to another phone. The last one claimed that the price of this offering technology should be paid because there are no much technologies in this area that apply the idea of tracking.

\subsection{Requirements}

After gathering the information in the previous step, we further extract some requirements from the user needs, and some from the domain itself, later on, classify them into functional and non-functional requirements.

\subsubsection{Functional Requirements}

Summarized in following: Login, Locate the Child, Track, Get Direction, Call.

The system shall let the user create an account and/ or login to it.

The system should let the user acquire the exact location of the other device with GPS.

The system must give the ability to the user to track the current location of the other device with GPS.

\subsubsection{Non-Functional Requirements}

Summarized in following: Security, Specifying Interval, Set Time, Simplicity, Very Fast Update of Location.

The system equipment has to be safe as stated in the interview.

The system has to quickly update the location of the other device, within a minute, as being suggested by one of the participants in the last part of the questionnaire.

The system has to be simple and easy to use hence the users are from various backgrounds, and it will be a new real experiment as concluded in Figure14. The system is better to be in the English language because almost all of the participants in the questionnaire agreed on that.

The system is preferred to have the ability in the child side to have a button that will notify the parent phone, but that's an extra requirement in our perception.

The system may have the tracker on a wearable wrist, that's also an extra requirement because currently, we will deal with core devices in our case.

\section{METHODOLOGIES}

This section will discuss the methodology that will be used in the research. In order to assure creating and having a high-quality software, the research is required to follow a certain software development life cycle (SDLC) framework. The framework properly defines the task to be performed at each step in the software development process which will make sure our work is planned, organized, and following the schedule. 


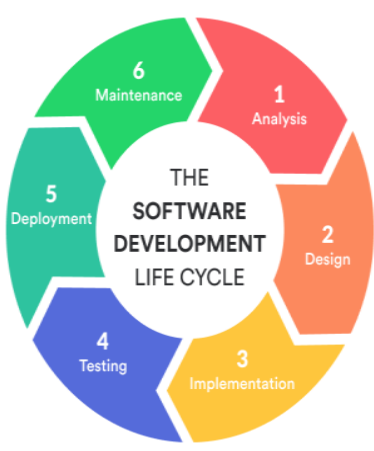

Fig 15: Methodology

There are various software development life cycle models in which the step sequence is unique to its type, therefore the models that our research will be using is incremental prototyping model [22]. The reason behind us using the incremental prototyping model is because it is so far suiting best considering the time and cost constraints. This way the functionality of the system will be divided into subdivision modules. Every single developed model will be assigned on each iteration and thus each iteration will depict the completion of the required functionality.

With the user involvement at the end of each iteration, this will increase the user satisfactory of the product.

Furthermore, the model enables the module or functionality with the highest priority place into the first iteration to be the first release with the subsequent iteration for the lower priority requirement.

We designed the system to contain the following use cases in the diagram, and then each one is elaborated. There are 8 use cases, can be divided as 2 for registration of parent and child, 3 for location and direction and geofence, and 2 for the common things between parent and child.

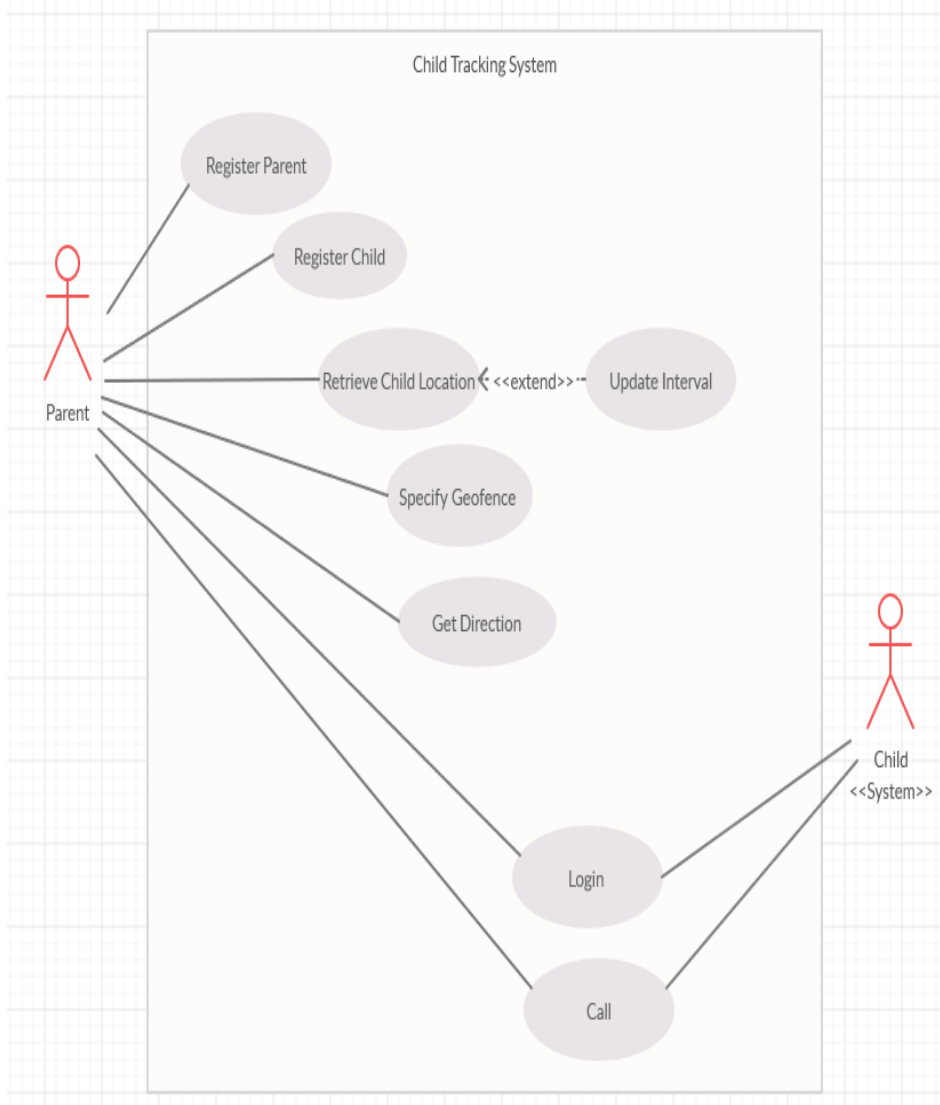

Fig 16: Child Tracking System Use Case

Table 4: Register Parent

\begin{tabular}{|l|l|}
\hline Use Case ID & 1 \\
\hline Use Case Name & Register Parent \\
\hline Actor & Parent \\
\hline Goal & Let the parent register parent account. \\
\hline Trigger & The parent is a new user. \\
\hline Precondition & $\begin{array}{l}\text { The parent need to get the login } \\
\text { credentials so further will login. }\end{array}$ \\
\hline Post condition & The parent account will be created. \\
\hline Normal Flow & $\begin{array}{l}\text { 1.Parent enters the username, email, } \\
\text { password and phone number. The } \\
\text { System checks if it's existed already or } \\
\text { not. } \\
\text { 2.Redirect the parent to login activity. }\end{array}$ \\
\hline $\begin{array}{l}\text { Alternative } \\
\text { Flow }\end{array}$ & $\begin{array}{l}\text { The parent entered existing account, the } \\
\text { system will ask to retry. }\end{array}$ \\
\hline
\end{tabular}




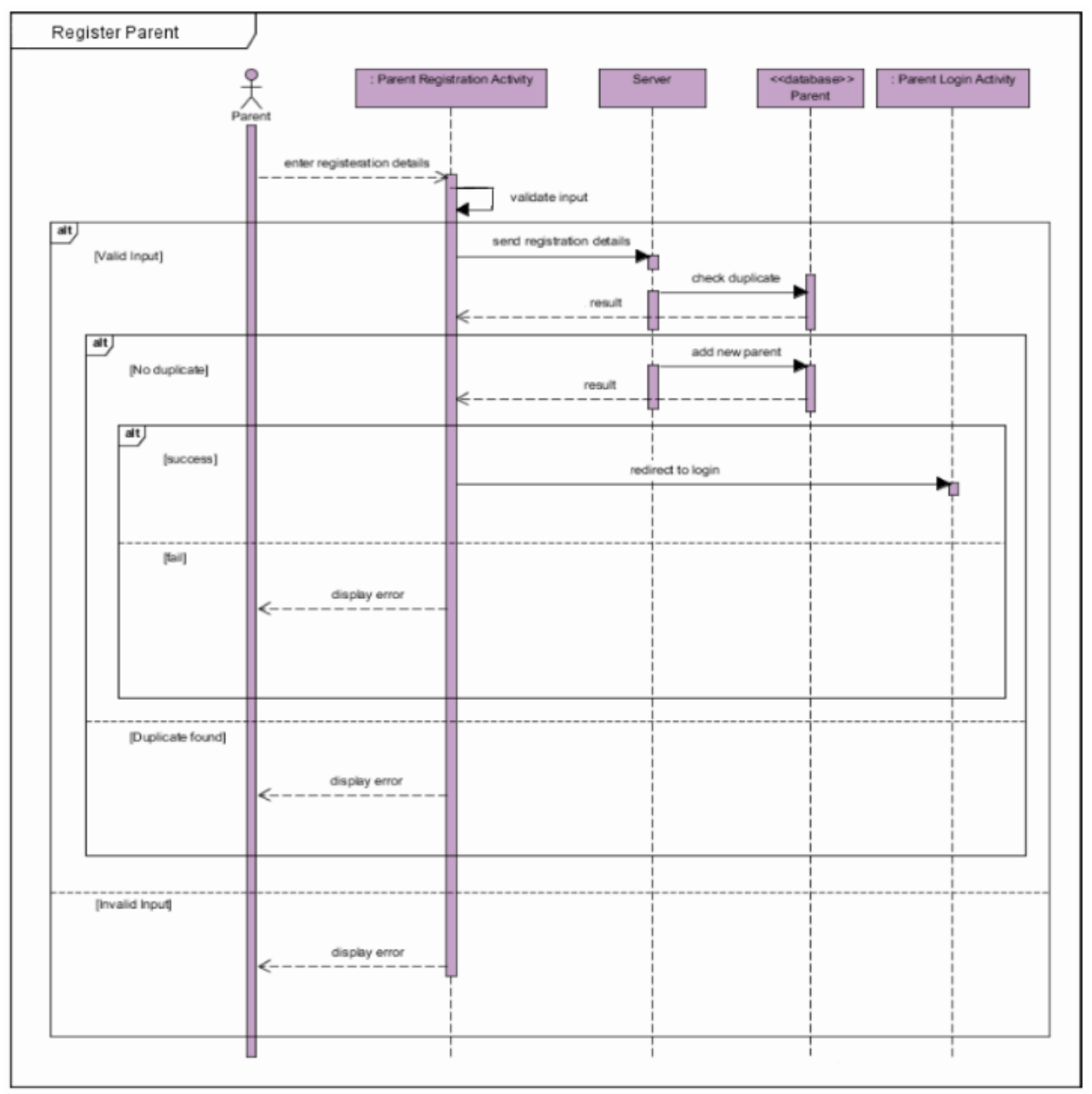

Fig 17: Register Parent

Table 5: Register Child

\begin{tabular}{|l|l|}
\hline Use Case ID & 2 \\
\hline Use Case Name & Register Child \\
\hline Actor & Parent \\
\hline Goal & Let the parent register child account. \\
\hline Trigger & $\begin{array}{l}\text { The parent is a new user who wants to } \\
\text { enter the child account. }\end{array}$ \\
\hline Precondition & The parent is registered. \\
\hline Post condition & The child account will be created. \\
\hline
\end{tabular}

\begin{tabular}{|l|l|}
\hline Normal Flow & $\begin{array}{l}\text { 1.Parent enters the username, email, } \\
\text { password and phone number. The } \\
\text { System checks if it's existed already or } \\
\text { not. } \\
\text { 2.Redirect the parent to main activity. }\end{array}$ \\
\hline $\begin{array}{l}\text { Alternative } \\
\text { Flow }\end{array}$ & $\begin{array}{l}\text { The parent entered existing account, the } \\
\text { system will ask to retry. }\end{array}$ \\
\hline
\end{tabular}




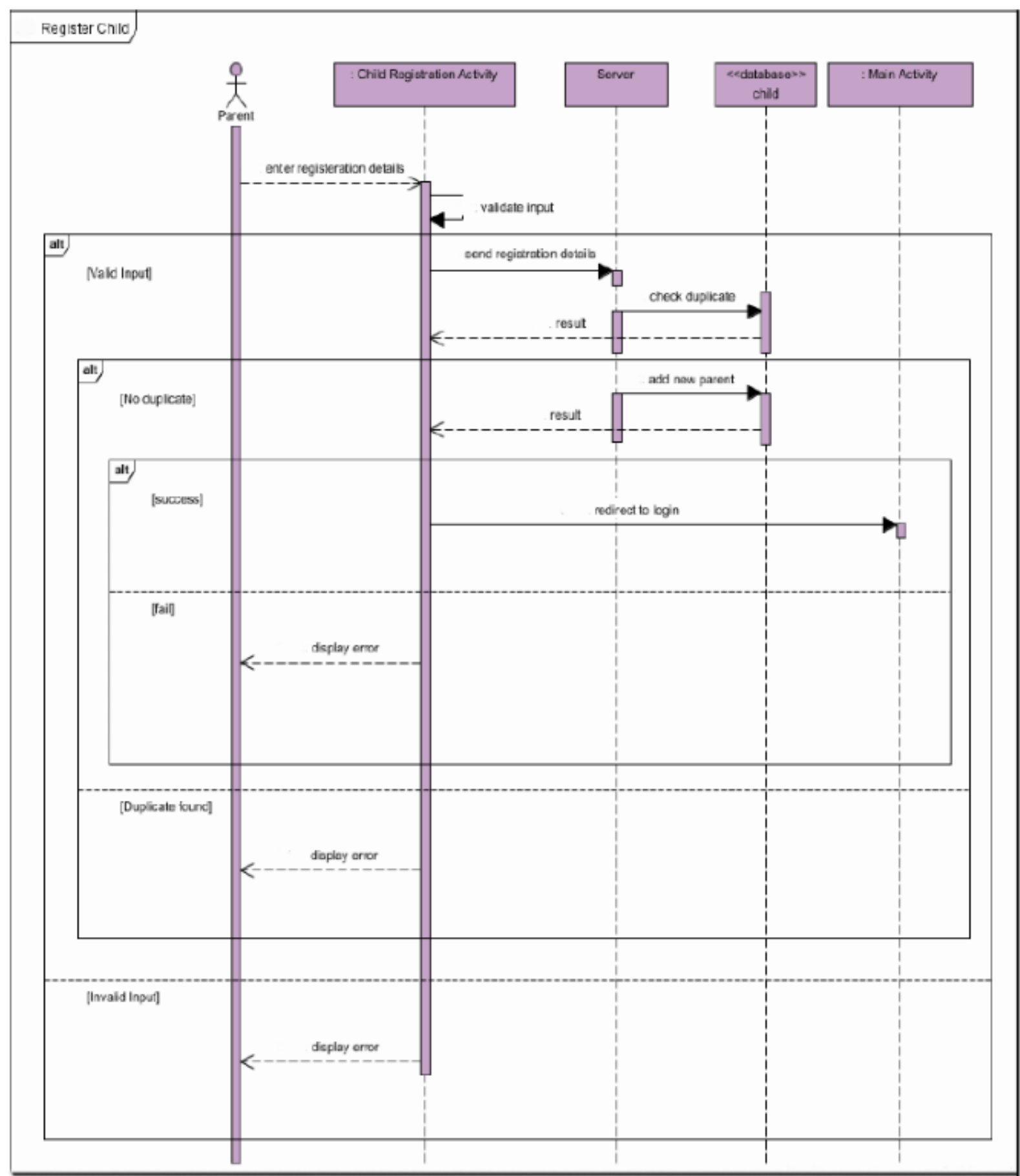

Fig 18: Register Child

\section{Table 6: Retrieve Child Location}

\begin{tabular}{|l|l|}
\hline Use Case ID & 3 \\
\hline Use Case Name & Retrieve Child Location \\
\hline Actor & Parent \\
\hline Goal & Let the parent get child location. \\
\hline Trigger & $\begin{array}{l}\text { The parent enters the map view or } \\
\text { manually clicks on child name the map. }\end{array}$ \\
\hline Precondition & $\begin{array}{l}\text { 1. The parent is entered in the map view. } \\
\text { 2. The child is logged in and connected. }\end{array}$ \\
\hline Post condition & The parent will get the child location. \\
\hline Normal Flow & $\begin{array}{l}\text { 1. The parent enter to the map view. The } \\
\text { system requests the server to get children } \\
\text { location, then send it to parent. }\end{array}$ \\
\hline
\end{tabular}

Alternative Flow
1. The parent clicks on the child name. The system requests the server to get children location, then send it to parent. 2. The parent configures the system to update location according to a given time set. The system requests the server to get children location, then send it to parent according to the time set.

3. The parent clicks on the child name but the child is not connected. The system will show an error message that child is not connected. 


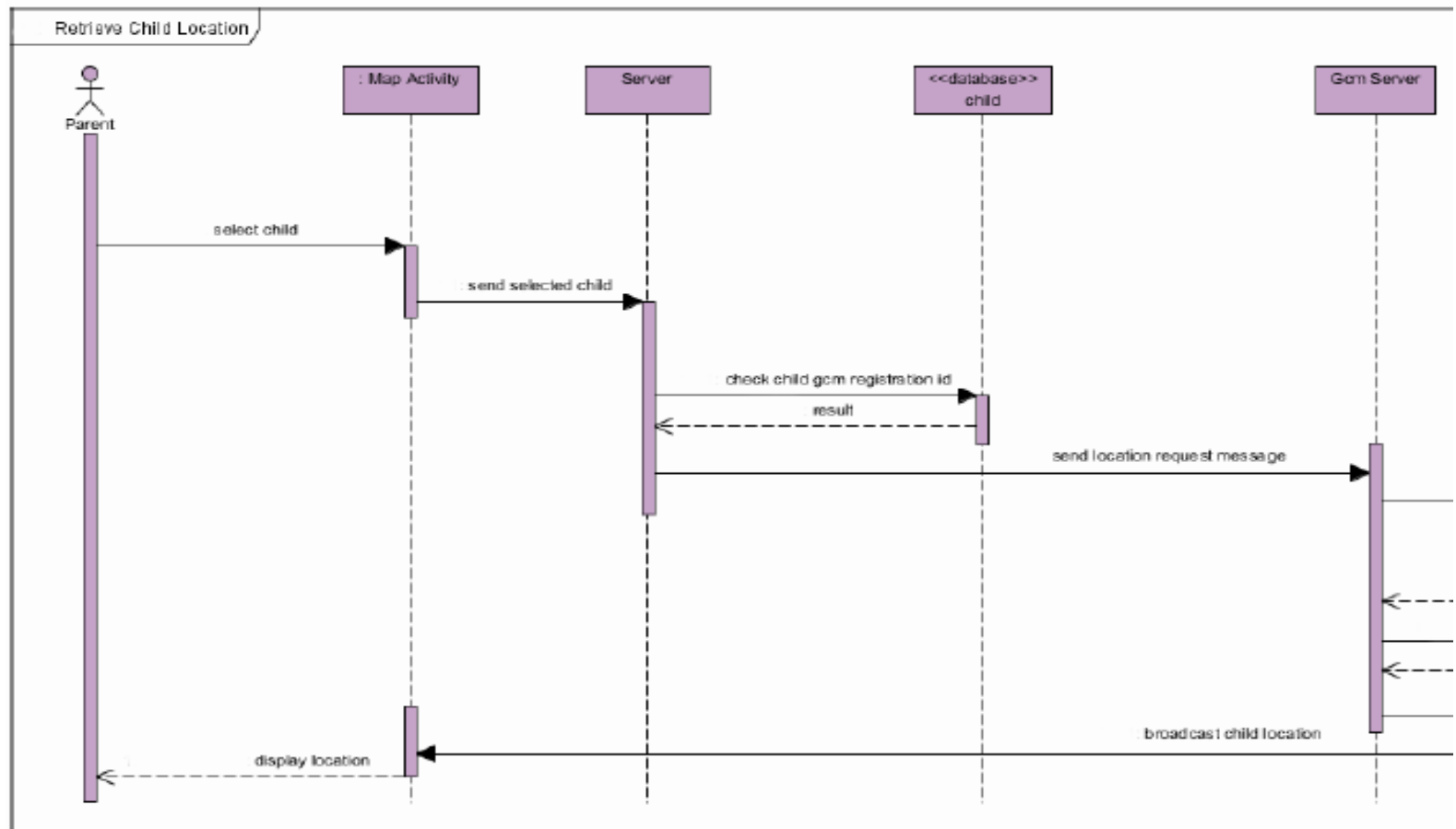

Fig 19: Register Child Location 1

Table 7: Update Interval

\begin{tabular}{|l|l|}
\hline Use Case ID & 4 \\
\hline Use Case Name & Update Interval \\
\hline Actor & Parent \\
\hline Goal & $\begin{array}{l}\text { Let the parent update the interval for } \\
\text { child location. }\end{array}$ \\
\hline Trigger & $\begin{array}{l}\text { The parent changes the location update } \\
\text { interval from settings. }\end{array}$ \\
\hline Precondition & The parent is registered. \\
\hline Post condition & The time interval will be changed. \\
\hline Normal Flow & $\begin{array}{l}\text { The parent enters the setting and changes } \\
\text { the location update interval. The system } \\
\text { will store the values and function } \\
\text { accordingly. }\end{array}$ \\
\hline $\begin{array}{l}\text { Alternative } \\
\text { Flow }\end{array}$ & $\begin{array}{l}\text { The parent enters wrong entry and the } \\
\text { system keep it to default value. }\end{array}$ \\
\hline
\end{tabular}

Table 8: Specify Geofence

\begin{tabular}{|l|l|}
\hline Use Case ID & 5 \\
\hline Use Case Name & Specify Geofence \\
\hline Actor & Parent \\
\hline Goal & $\begin{array}{l}\text { Let the parent specify the Geofence area } \\
\text { for child location. }\end{array}$ \\
\hline Trigger & $\begin{array}{l}\text { The parent wants to specify the area for } \\
\text { child location. }\end{array}$ \\
\hline Precondition & The child is logged in and connected. \\
\hline Post condition & The geofence will be specified. \\
\hline Normal Flow & $\begin{array}{l}\text { The parent specifies the circle area to be } \\
\text { watched along with the duration. The } \\
\text { system sends the chooses to server then }\end{array}$ \\
\hline
\end{tabular}

\begin{tabular}{|l|l|}
\hline & $\begin{array}{l}\text { further the server sends it to child to start } \\
\text { watching and if the Geofence is triggered } \\
\text { the parent will be notified. }\end{array}$ \\
\hline $\begin{array}{l}\text { Alternative } \\
\text { Flow }\end{array}$ & $\begin{array}{l}\text { The parent can't create multiple } \\
\text { Geofences at the same area, if he/she } \\
\text { tries he/she won't be able to do. }\end{array}$ \\
\hline
\end{tabular}

Table 9: Get Direction

\begin{tabular}{|l|l|}
\hline Use Case ID & 6 \\
\hline Use Case Name & Get Direction \\
\hline Actor & Parent \\
\hline Goal & Let The parent get child's location. \\
\hline Trigger & Parent wants to go to child location. \\
\hline Precondition & The parent is connected. \\
\hline Post condition & $\begin{array}{l}\text { The parent will be directed to the } \\
\text { location using Google Maps. }\end{array}$ \\
\hline Normal Flow & $\begin{array}{l}\text { 1.Parent clicks on child marker. The } \\
\text { system will pop up an icon to get } \\
\text { direction. } \\
\text { 2.Parent clicks the icon. The system } \\
\text { redirects the parent to Google Maps } \\
\text { direction. Further it gets the child } \\
\text { location and displays the location. }\end{array}$ \\
\hline $\begin{array}{l}\text { Alternative } \\
\text { Flow }\end{array}$ & $\begin{array}{l}\text { The access to Google Maps is denied so } \\
\text { this process can't be happened. }\end{array}$ \\
\hline
\end{tabular}

\section{Table 10: Login}

\begin{tabular}{|l|l|}
\hline Use Case ID & 7 \\
\hline Use Case Name & Login \\
\hline Actor & Parent and/or Child \\
\hline
\end{tabular}


22542-22557, 2020

\begin{tabular}{|l|l|}
\hline Goal & $\begin{array}{l}\text { To let the parent and/or Child login and } \\
\text { be authenticated. }\end{array}$ \\
\hline Trigger & Parent and/or Child wants to login. \\
\hline Precondition & $\begin{array}{l}\text { Parent and/or Child are registered } \\
\text { already. }\end{array}$ \\
\hline Post condition & $\begin{array}{l}\text { Parent and/or Child will enter their own } \\
\text { main activity. }\end{array}$ \\
\hline Normal Flow & $\begin{array}{l}\text { 1.Parent enters the email and password. } \\
\text { The System checks if it's matching or } \\
\text { not. } \\
\text { 2.The parent is logged in. } \\
\text { 3.Parent and/or Child enters the email } \\
\text { and password of child. The System } \\
\text { checks if it's matching or not. } \\
\text { 4.The child is logged in. }\end{array}$ \\
\hline Alternative & $\begin{array}{l}\text { Parent and/or Child enters wrong email } \\
\text { and/or password. The system will ask to } \\
\text { retry. }\end{array}$ \\
\hline
\end{tabular}

Table 11: Call

\begin{tabular}{|l|l|}
\hline Use Case ID & 8 \\
\hline Use Case Name & Call \\
\hline Actor & Parent and/or Child \\
\hline Goal & $\begin{array}{l}\text { To let the parent call the child or the } \\
\text { child call the parent. }\end{array}$ \\
\hline Trigger & $\begin{array}{l}\text { Parent and/or Child wants to contact } \\
\text { with each other via call. }\end{array}$ \\
\hline Precondition & $\begin{array}{l}\text { The parent need to specify the child and } \\
\text { has already entered the phone number of } \\
\text { child. }\end{array}$ \\
\hline Post condition & The call will be made. \\
\hline Normal Flow & $\begin{array}{l}\text { The parent clicks the call button. The } \\
\text { system searches for child phone number } \\
\text { then dial. }\end{array}$ \\
\hline $\begin{array}{l}\text { Alternative } \\
\text { Flow }\end{array}$ & $\begin{array}{l}\text { The dial can't be done unless the access } \\
\text { to calls is given. }\end{array}$ \\
\hline
\end{tabular}

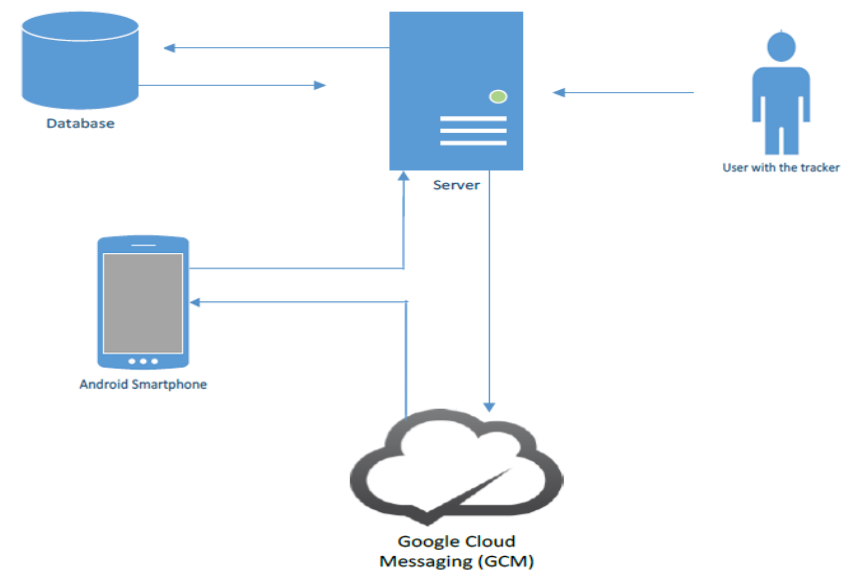

Fig 20: Deployment Diagram

The proposed solution to the problem of the drifting of the children or the old people or the disabled persons in Al-Masjid Al-Nabawi is as the following:
The parent or the person is responsible and want to request the tracking system will come to the center with the child or the old person or the disable person, then he will download the application and create an account, and after that the other person will get the tracking device or mobile which will be for that particular person only.

\section{CONCLUCION}

The benefits of this proposed solution that it will reduce the time to look up for the missing person, not just that but may prevent the lose even before getting the person drifted away, which leads to fast recovery. Lastly, it will also reduce the time the child will sit in the Child Care Center in Al-Masjid Al-Nabawi. This system does not include indoor positioning solutions where it uses to locate the child indoor. Our application requires an active connection between the internet and need to operate on an active phone. Lastly, a web view is not provided. It decrease the cases of missing persons, especially the children. It gives a tracking solution for the parent to keep tracking their children location in the Al-Haram by using GPS with GLONASS to improve the tracking accuracy and availability. It gives parents a solution to find their child in just a click in case of emergency to know the whereabouts of the child. It also gives away to schedule and monitor certain areas to get alerted when their child reaches or leaves his or her proximity area.

\section{REFERENCES}

[1] Saudi Press Agency (2019, August). Statistics of Hajj season in 1440 A.H. https://sabq.org/GnqgBR

[2] The General Presidency for the affairs of the Grand Mosque and the Prophet's Mosque. Statistics about Al-Masjid Al-Nabawi. http://www.wmn.gov.sa/news/5002/4/رمارة المسجد-النبوي / المي

[3] Saudi Press Agency (2018, June). The Role of Child Care Center in Al Masjid Al-Nabawi. https://www.spa.gov.sa/1775040

[4] Garmin, 2016. What is GPS? http://www8.garmin.com/aboutGPS/ 
[5] Gps.gov., 2016. GPS.gov: "How GPS Works" Poster. http://www.gps.gov/multimedia/poster/

[6] NAVSTAR GPS, 1996. Navstar GPS User Equipment, Introduction, Public Release Version 1.

[7] Moskvitch K. (2016). Glonass: Has Russia's satnav system come of age? BBC News http://news.bbc.co.uk/2/hi/8595704.stm

[8] Polischuk, Kozlov, Ilitchov (2002). The global navigation satellite system GLONASS: Development and usage in the 21st century. Russian Aerospace Agency, Moscow, Russia.

[9] Eissfeller, Ameres, Kropp (2007). Performance of GPS, GLONASS and Galileo. Photogrammetric Week. Vol. 7, pp. 185-199.

[10] Lee C. H. (2016). Child tracking system. Faculty of Engineering and Science, Universiti Tunku Abdul Rahman, Malaysia.

[11] SDCM, 2016. Precision of GLONASS/GPS navigation definitions. http://www.sdcm.ru/smglo/stparam?version=en g\&repdate\&site $=$ extern

[12] Maghade Satish, Chavhan Nandlal, Gore Sandip (2015, April). Child Tracking System using Android phones. International Journal of Advanced Research in Computer Engineering \& Technology (IJARCET). Volume 4 Issue 4.

[13] Rita H. Pawade, Dr Arun N. Gaikwad (2015, June). Android Based Children Tracking System. International Journal of Science, Engineering and Technology Research (IJSETR), Volume 4, Issue 6. ISSN:2278 - 7798.

[14] Missawi, Mo'men Hassan (2015). Sudan University of Science and Technology, College of Computer Science \& Information Technology.

[15] Yuvraj Rathod, Manoj Dighole, Ritu Sharma (2018, March). Implementation of Children Tracking System on Android Mobile Terminals. International Research Journal of Engineering and Technology

[16] Tanweer Alam, Mohamed Benaida. "Blockchain and Internet of Things in Higher Education.", Universal Journal of Educational Research. 8.5 (2020) 2164 - 2174. doi: 10.13189/ujer.2020.080556.

[17] Tanweer Alam. Shamimul Qamar. Amit Dixit. Mohamed Benaida. " Genetic Algorithm: Reviews, Implementations, and Applications.",
International Journal of Engineering Pedagogy (iJEP). 2020.

[18] Tanweer Alam. Mohamed Benaida. "Blockchain, Fog and IoT Integrated Framework: Review, Architecture and Evaluation.", Technology Reports of Kansai University. Vol 62(2). 2020.

[19] Tanweer Alam. "A Reliable Framework for Communication in Internet of Smart Devices using IEEE 802.15.4.", ARPN Journal of Engineering and Applied Sciences. Vol 13(10). 2018.

[20] Tanweer Alam. Mohamed Benaida. "CICS: Cloud-Internet Communication Security Framework for the Internet of Smart Devices.", International Journal of Interactive Mobile Technologies (iJIM). Vol 12(6). 2018. DOI: 10.3991/ijim.v12i6.6776

[21] Tanweer Alam. Mohamed Benaida. "The Role of Cloud-MANET Framework in the Internet of Things (IoT).", International Journal of Online Engineering. Vol 14(12). 2018. DOI: 10.3991/ijoe.v14i12.8338

[22] Alam, Tanweer. "Fuzzy control based mobility framework for evaluating mobility models in MANET of smart devices." ARPN Journal of Engineering and Applied Sciences 12, no. 15 (2017): 4526-4538.

Cite this article as follows.

Tanweer Alam, Abdirahman Ahmed Hadi, Rayyan Qari Shahabuddin Najam, Shamimul Qamar. Design a Mobile Application for Children's Tracking in Crowded Environments. TEST Engineering and Management, Vol 83, pp. 22542-22557, 2020 